\title{
$\mathrm{SiC}$ 繊維強化 Al 複合材の拡散現象
}

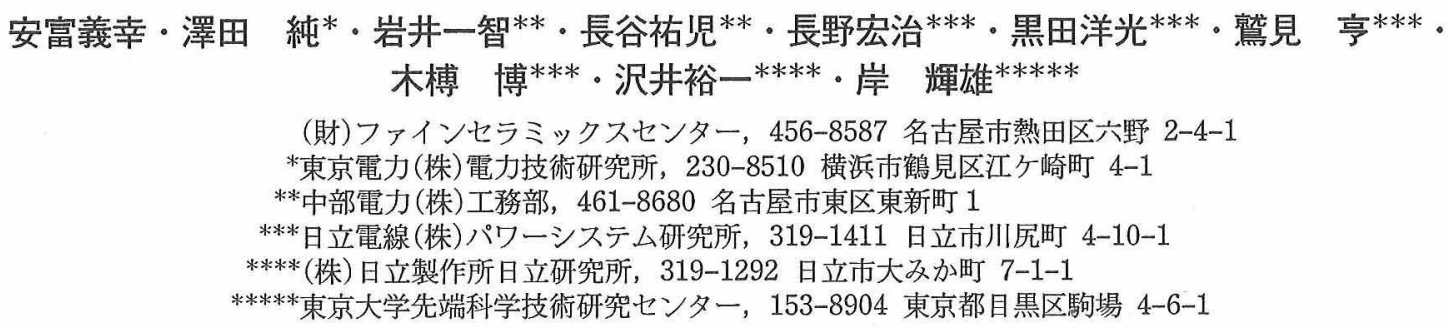

\section{Diffusion Phenomena in SiC Fiber-Reinforced Aluminum Composite}

Yoshiyuki YASUTOMI, Jun SAWADA, ${ }^{*}$ Kazutomo IWAI, ${ }^{* *}$ Yuji HASE, ${ }^{* *}$ Kouji NAGANO, *** Hiromitsu KURODA, ${ }^{* * *}$ Tohru SUMI, ${ }^{* * *}$ Hiroshi KOGURE, ${ }^{* * *}$ Yuichi SAWAI**** and Teruo KISHI****

\footnotetext{
Japan Fine Ceramics Center, 2-4-1, Mutsuno, Atsuta-ku, Nagoya-shi 456-8587

*Tokyo Electric Power Co., 4-1, Egasaki-cho, Tsurumi-ku, Yokohama-shi 230-8510

**Chubu Electric Power Co., 1, Toshin-cho, Higashi-ku, Nagoya-shi 461-8680

****ower System Lab., Hitachi Cable, Ltd., 4-10-1, Kawajiri-cho, Hitachi-shi 319-1411

****Hitachi Res. Lab., Hitachi Ltd., 7-1-1, Omika-cho, Hitachi-shi 319-1292

******RCAST, The University of Tokyo, 4-6-1, Komaba, Meguro-ku, Tokyo 153-8904
}

\begin{abstract}
If electrical power is transmitted by a power cable made of $\mathrm{SiC}$ fiber-reinforced aluminum, Al atoms diffuse into the reinforcement fiber at the transmission temperature. In this study, the diffusion coefficients of Al atoms in Hi-Nicalon ${ }^{\text {TM}} / \mathrm{Al}$ system and Nicalon ${ }^{\mathrm{TM}} / \mathrm{Al}$ system were calculated. The outcomes of this study can be summarized as follows: (1) Diffusion coefficient of Al atoms in the Hi-Nicalon ${ }^{\mathrm{TM}} \mathrm{SiC}$ fiber is $\mathbf{1 0}^{-3}$ times smaller than that of Nicalon ${ }^{\mathrm{TM}} \mathrm{SiC}$ fiber at transmission temperature between $300^{\circ} \mathrm{C}$ and $600^{\circ} \mathrm{C}$. (2) Activation energy $Q$ of $\mathrm{Al}$ diffusion in the two different $\mathrm{SiC}$ fibers are the same, but frequency factor $D_{0}$ of $\mathrm{Hi}$ Nicalon ${ }^{\text {TM }}$ SiC fiber is smaller than that of Nicalon ${ }^{\mathrm{TM}} \mathrm{SiC}$ fiber. (3) Diffusion coefficient of Al in the SiC fiber is related to the microcrystallite of the SiC fiber. [Received September 21, 1998; Accepted February 19, 1999]
\end{abstract}

Key-words : Electrical power cable, SiC fiber reinforced Aluminum composite, SiC fiber, Al diffusion, Interface reaction, Activation energy, Frequency factor, TEM analysis, EDS analysis

\section{1. 緒 言}

電力需要の増加に伴い大容量送電が可能な軽量・高耐熱性の 電線が要求されている1)。そこで，既設鉄塔をそのまま使用で き，大容量の送電が可能で，かつ送電中の発熱によるたわみが 小さくできる次世代の $\mathrm{SiC}$ 繊維強化 $\mathrm{Al}$ 複合電線の開発を進め ている2) 6).

$\mathrm{SiC} / \mathrm{Al}$ 複合材の界面反応，機栈的特性に関する研究は多く の報告がなされている7) 17)。しかし， $\mathrm{SiC}$ 繊維/A1の界面反 応現象に関する詳細な報告は少ない。著者らは，既に $\mathrm{SiC}$ 織 維（日本カーボン製, Nicalon ${ }^{\mathrm{TM}}$; Si : 63.7, C : 35.8, O : 12.3 mass\%）を用いた $\mathrm{SiC}$ 䋐維強化 $\mathrm{Al}$ 複合電線の界面反応につい て詳細に分析し， $\mathrm{SiC}$ 繊維/ $\mathrm{Al}$ 界面での反応現象を把握してい $ろ^{3) \sim 5)}$. 同時に, 複合電線のさらなる高強度化, 高信頼性化 を目的に酸素含有量が小さく高強度の $\mathrm{SiC}$ 繊維（日本カーボ 製，Hi-Nicalon ${ }^{\mathrm{TM}}: \mathrm{Si}: 62.4, \mathrm{C}: 37.1, \mathrm{O}: 0.5$ mass\%）を用 いた複合電線の製造条件を検討し，既報では複合電線製造プロ セスに打ける溶融 $\mathrm{Al}$ と $\mathrm{SiC}$ 繊維の反応について明らかにし $た^{6)}$. 一方，いったん製造した $\mathrm{SiC} / \mathrm{Al}$ 複合電線を使用する際, 送電中に $\mathrm{Al}$ が $\mathrm{SiC}$ 繊維内へ拡散する現象が認められた． $\mathrm{SiC}$ 繊維は, 前駆体を熱分解することにより得られ, $\mathrm{SiC}$ 微結晶が Si-C-Oアモルファス相中に散在している構造となってい る18 20).これは, $\mathrm{SiC}$ の単結晶や多結晶焼結体とは根本的に 違った構造であり， $\mathrm{SiC}$ 緎維中の $\mathrm{Al}$ 拡散挙動は $\mathrm{SiC}$ 焼結体中 のそれとは異なることが予想される，本報告では，複合電線の 使用条件下, $\mathrm{Al}$ の融点以下の温度領域で $\mathrm{SiC}$ 緎維中への $\mathrm{Al}$
の拡散に着目し, Nicalon ${ }^{\mathrm{TM}}$ 繊維及び Hi-Nicalon ${ }^{\mathrm{TM}}$ 繊維につ いて，Al の拡散係数を計算し，比較検討した。

\section{2. 実験方法}

\section{1 複合線の製造法}

$\mathrm{SiC}$ 繊維強化 $\mathrm{Al}$ 複合線の製造工程を以下に記す． $\mathrm{SiC}$ 繊維 には日本カーボン製の Nicalon TM 及び Hi-Nicalon ${ }^{\mathrm{TM}}$ を用いた。 $\mathrm{SiC}$ 織維/ $\mathrm{Al}$ プリフォームワイヤーは, 純度 $99.99 \%$ 以上の $\mathrm{Al}$ 溶湯中 $\left(700^{\circ} \mathrm{C}\right)$ に $\mathrm{SiC}$ 織維を浸して巻取る方法で連続的に作 製する。プリフォームワイヤー断面は円形に近く，直径約 $0.85 \mathrm{~mm}$ である. プリフォームワイヤー7本を束ねて巻取り ながら，再度 $\mathrm{Al}$ 溶湯中に浸漬し，ダイスを通過させて，直径 約 $3.0 \mathrm{~mm}$ の $\mathrm{SiC}$ 繊維 $/ \mathrm{Al}$ 複合線とする．次に，押出し法によ り, $\mathrm{SiC}$ 繊維 $/ \mathrm{Al}$ 複合線表面に $\mathrm{Al}$ を被覆させる。これにより， 繊維体積率 $17.8 \%$, 直径 $3.5 \mathrm{~mm}$ の $\mathrm{SiC}$ 䋐維 $/ \mathrm{Al}$ 複合素線を得 る．実際の架空電線として使用するためには， $\mathrm{SiC}$ 繊維/Al 複 合素線37本をより合わせ直径 $24.5 \mathrm{~mm}$ のより線にする。なお， 製造後の複合素線の $\mathrm{SiC}$ 繊維/ $\mathrm{Al}$ 界面には反応生成物がないこ とを確認している5),6).

\section{2 界面の解析方法}

本研究での評価用試料には, $\mathrm{SiC}$ 繊維/ $\mathrm{Al}$ 複合電線の使用条 件下，つまり $\mathrm{Al}$ の融点以下での温度条件での $\mathrm{Al}$ の拡散現象 を速度論的に考察するために，複合素線を $300^{\circ} \mathrm{C} ら 600^{\circ} \mathrm{C}$ の 範囲で空気中で所定時間熱処理した試料を準備した．熱処理後 の複合素線中の界面の詳細な観察は，透過型電子顕微鏡 
(TEM ; 日立製作所製, H-9000NAR; $300 \mathrm{kV})$ 及びエネル ギー分散型 X 線分光分析 (EDX; Gatan 社 製) を用いた. TEM 観察用試料の作製は通常のイオンミリング法で行った. 本試料 は, 硬度が大きく異なる 2 相より構成されるため, TEM 観察 で視野を確認しながらイオンミリング処理を行った． $\mathrm{Al}$ 濃度 の測定は, 界面に反応生成物のない個所で, 界面から $\mathrm{SiC}$ 䋐 維側に $20 \sim 400 \mathrm{~nm}$ の範囲で行った. 複合素線製造時の $\mathrm{SiC}$ 繊 維と $\mathrm{Al}$ 溶湯との反応において $\mathrm{SiC}$ 繊維中に $\mathrm{Al}$ が拡散してい ることを確認しており5),6), 測定の際には, 製造過程で $\mathrm{SiC}$ 䋐 維中に拡散した $\mathrm{Al}$ 濃度を差し引くことにより, 複合電線使用 時の $\mathrm{Al}$ 拡散量を求めた.

\section{3. 結果及び考察}

\subsection{Nicalon $^{\mathrm{TM}}$ 繊維中への Al の拡散}

大気中, $300^{\circ} \mathrm{C} ら 600^{\circ} \mathrm{C}$ の各温度で熱処理した後の Nicalon ${ }^{\mathrm{TM}}$ 繊維中の $\mathrm{Al}$ の濃度を $\mathrm{SiC} / \mathrm{Al}$ 界面からの距離の関 数として求めた結果を図 1 の実線に示す. 熱処理温度が高いほ ど, Nicalon ${ }^{\mathrm{TM}}$ 繊維中へ多くの $\mathrm{Al}$ 原子が移動していることが 分かる。ここで，この $\mathrm{Al}$ 原子の移動現象が Fick の法則に従 うと仮定し, Nicalon ${ }^{\mathrm{TM}}$ 繊維中への $\mathrm{Al}$ 原子の拡散係数を計算 する。

界面から $\mathrm{SiC}$ 繊維内部の位置を $x$ で表し, 界面 $(x=0)$ に 抢ける $\mathrm{Al}$ 濃度を $C^{\prime}$ とし， $C^{\prime}$ は一定であると仮定する. $x$ に おける $\mathrm{Al}$ 濃度 $C(x, t)$ が Fick の第 2 法則の一般的な解とし て次式に与えられる.

$$
C(x, t)=C^{\prime}\left(1-\operatorname{erf}\left(x / 2(D t)^{1 / 2}\right)\right.
$$

以下に, 各条件での拡散係数 $D$ を(1)式を用いて求める.

(1) $300^{\circ} \mathrm{C} \times 18 \mathrm{Ms}$

$t=18 \mathrm{Ms}$ における $x=100 \mathrm{~nm}$ 及び $400 \mathrm{~nm}$ での $\mathrm{Al}$ 濃度を用 いて拡散係数 $D$ を求める. 図 1 より, $x=100 \mathrm{~nm}, 400 \mathrm{~nm}$ に おいてCはおのおの $2.1 \mathrm{~mol} \%, 1.3 \mathrm{~mol} \%$ あるから，

$$
\begin{aligned}
& 2.1=C^{\prime}\left(1-\operatorname{erf}\left(1 \times 10^{-7} / 2(0.3 D)^{1 / 2}\right)\right. \\
& 1.3=C^{\prime}\left(1-\operatorname{erf}\left(4 \times 10^{-7} / 2(0.3 D)^{1 / 2}\right)\right.
\end{aligned}
$$

これより, Nicalon ${ }^{\mathrm{TM}}$ 繊維中への $\mathrm{Al}$ の拡散係数 $D=1.1 \times$ $10^{-20} \mathrm{~m}^{2} / \mathrm{s}$ が求まる.ここで, $\mathrm{SiC}$ 緎維中への $\mathrm{Al}$ の固溶限は 1 mass\%程度である ${ }^{21)}$ が, Nicalon ${ }^{\mathrm{TM}}$ 繊維は Si-C-O アモル ファスと $\mathrm{SiC}$ 微結晶の集合体18) 20)であるため, 見掛け上, 固 溶限以上の $\mathrm{Al}$ の存在が許されるものと考えられる。

(2) $500^{\circ} \mathrm{C} \times 1.9 \mathrm{Ms}$

$t=1.9 \mathrm{Ms}$ における $x=100 \mathrm{~nm}$ 及び $400 \mathrm{~nm}$ での $\mathrm{Al}$ 濃度を

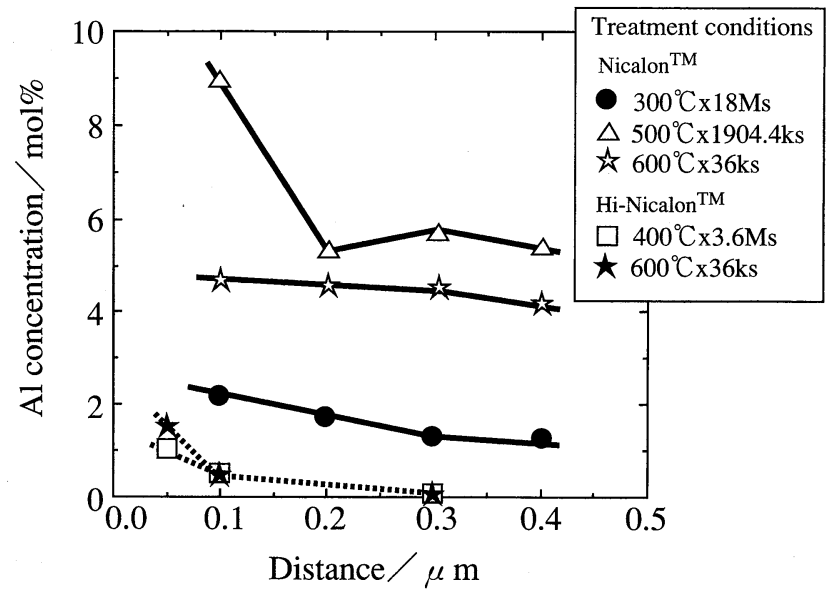

Fig. 1. $\mathrm{Al}$ concentration $[\mathrm{Al}(\mathrm{Al}+\mathrm{Si})]$ in $\mathrm{SiC}$ fiber as a function of the distance from the interface to the $\mathrm{SiC}$ fiber side.
用いて拡散係数 $D$ を求める。同じく，図 1 から $x$ に対応する Cを読み取り，

$$
\begin{aligned}
& 8.9=C^{\prime}\left(1-\operatorname{erf}\left(1 \times 10^{-7} / 2(0.3 D)^{1 / 2}\right)\right. \\
& 5.4=C^{\prime}\left(1-\operatorname{erf}\left(4 \times 10^{-7} / 2(0.3 D)^{1 / 2}\right)\right.
\end{aligned}
$$

これより, Nicalon ${ }^{\mathrm{TM}}$ 繊維中への $\mathrm{Al}$ の拡散係数 $D=1.2 \times$ $10^{-19} \mathrm{~m}^{2} / \mathrm{s}$ が求まる.

(3) $600^{\circ} \mathrm{C} \times 36 \mathrm{ks}$

$t=36 \mathrm{ks}$ における $x=100 \mathrm{~nm}$ 及び $400 \mathrm{~nm}$ での $\mathrm{Al}$ 濃度を用 いて拡散係数 $D$ を求める. 図 1 から $x$ に対応する $C$ を読み取 $\eta$,

$$
\begin{aligned}
& 4.7=C^{\prime}\left(1-\operatorname{erf}\left(1 \times 10^{-7} / 2(0.3 D)^{1 / 2}\right)\right. \\
& 4.2=C^{\prime}\left(1-\operatorname{erf}\left(4 \times 10^{-7} / 2(0.3 D)^{1 / 2}\right)\right.
\end{aligned}
$$

これより, Nicalon ${ }^{\mathrm{TM}}$ 繊維中への $\mathrm{Al}$ の拡散係数 $D=1.4 \times$ $10^{-17} \mathrm{~m}^{2} / \mathrm{s}$ が求まる.

得られた各温度と拡散係数 $D$ との関係を図 2 の実線に示す.

\section{$3.2 \mathrm{Hi}$-Nicalon ${ }^{\mathrm{TM}}$ 繊維中への $\mathrm{Al}$ の拡散}

Hi-Nicalon ${ }^{\mathrm{TM}} \mathrm{SiC}$ 繊維中への $\mathrm{Al}$ の拡散速度を求める。 $400^{\circ} \mathrm{C} \times 3.6 \mathrm{Ms}$ 処理品及び $600^{\circ} \mathrm{C} \times 36 \mathrm{ks}$ 処理品について TEM-EDX 分析を行った．分析結果を図 1 の破線で示す. 3.1 節と同様に, 各条件の固相反応での Hi-Nicalon ${ }^{\mathrm{TM}}$ 繊維中への $\mathrm{Al}$ の拡散係数 $D$ を求める.

(1) $400^{\circ} \mathrm{C} \times 3.6 \mathrm{Ms}$

$t=3.6 \mathrm{Ms}$ における $x=50 \mathrm{~nm}$ 及び $100 \mathrm{~nm}$ での $\mathrm{Al}$ 濃度を用 いて拡散係数 $D$ を求める.

$$
\begin{aligned}
& 1.08=C^{\prime}\left(1-\operatorname{erf}\left(5 \times 10^{-8} / 2(0.3 D)^{1 / 2}\right)\right. \\
& 0.43=C^{\prime}\left(1-\operatorname{erf}\left(1 \times 10^{-7} / 2(0.3 D)^{1 / 2}\right)\right.
\end{aligned}
$$

これより, Hi-Nicalon ${ }^{\mathrm{TM}}$ 繊維中への $\mathrm{Al}$ の拡散係数 $D=9.2 \times$ $10^{-22} \mathrm{~m}^{2} / \mathrm{s}$ が求まる.ここで, Hi-Nicalon ${ }^{\mathrm{TM}}$ 繊維は $\mathrm{SiC}$ 微結 晶の含有率は高いが, 基本的な構造は Nicalon ${ }^{\mathrm{TM}}$ 繊維と同じ であり，したがって見掛け上，固溶限以上の $\mathrm{Al}$ の存在が許さ れると考えられる.

(2) $600^{\circ} \mathrm{C} \times 36 \mathrm{ks}$

$t=36 \mathrm{ks}$ における $x=50 \mathrm{~nm}$ 及び $100 \mathrm{~nm}$ での $\mathrm{Al}$ 濃度を用い て拡散係数 $D$ を求める.

$$
\begin{aligned}
& 1.57=C^{\prime}\left(1-\operatorname{erf}\left(5 \times 10^{-8} / 2(0.3 D)^{1 / 2}\right)\right. \\
& 0.41=C^{\prime}\left(1-\operatorname{erf}\left(1 \times 10^{-7} / 2(0.3 D)^{1 / 2}\right)\right.
\end{aligned}
$$

これより, Hi-Nicalon ${ }^{\mathrm{TM}}$ 繊維中への $\mathrm{Al}$ の拡散係数 $D=5.4 \times$

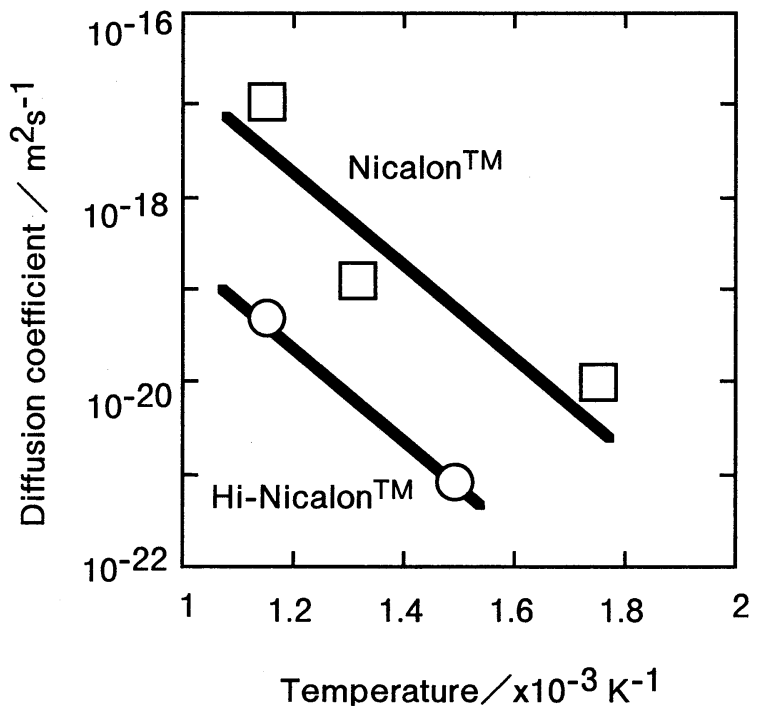

Fig. 2. Comparison of diffusion coefficient of $\mathrm{Al}$ into two different $\mathrm{SiC}$ fibers. 
$10^{-20} \mathrm{~m}^{2} / \mathrm{s}$ が求まる.

前記で得られた各温度と拡散係数との関係を Nicalon ${ }^{\mathrm{TM}}$ 繊維 の結果と合わせて図 2 に示す。各温度での拡散係数は，HiNicalon ${ }^{\mathrm{TM}}$ 絨維が Nicalon ${ }^{\mathrm{TM}}$ 緘維に比較して約 3 けた小さく， おのおのの拡散係数を表す 2 本の直線がほぼ平行であるとい う特徵がある。

各 $\mathrm{SiC}$ 繊維中への $\mathrm{Al}$ の拡散の活性化エネルギー $Q$, 頻度因 子 $D_{0}$ を求める.

$$
D=D_{0} \cdot \exp (-Q / R T) \text { より, }
$$

Nicalon ${ }^{\mathrm{TM}}$ 繊維 は $Q=100 \mathrm{~kJ} / \mathrm{mol}, D_{0}=1.2 \times 10^{-11} \mathrm{~m}^{2} / \mathrm{s}$, HiNicalon ${ }^{\mathrm{TM}}$ 繊維は $Q=98 \mathrm{~kJ} / \mathrm{mol}, D_{0}=3.8 \times 10^{-14} \mathrm{~m}^{2} / \mathrm{s}$ が求ま る. 活性化エネルギーはほとんど同じであるが，頻度因子 $D_{0}$ が 3 けた異なる。図 3 に製造後の Nicalon ${ }^{\mathrm{TM}}$ 繊維及び HiNicalon ${ }^{\mathrm{TM}}$ 緎維と $\mathrm{Al}$ との界面近傍の TEM 像を示す．先ほど 述べたように, Hi-Nicalon ${ }^{\mathrm{TM}}$ 繊維は $\mathrm{SiC}$ 微結晶が $\mathrm{Si}-\mathrm{C}-\mathrm{O}$ ア モルファスで結合された構造であるのに対して，Nicalon ${ }^{\mathrm{TM}}$ 絨 維は $\mathrm{SiC}$ 微結晶がほとんどない Si-C-O アモルファス相のみ である18) 20). 両者の中での $\mathrm{Al}$ 原子の移動に関する活性化工 ネルギーがほとんど等しいのは， $\mathrm{Al}$ が $\mathrm{SiC}$ 繊維中の $\mathrm{Si}-\mathrm{C}-\mathrm{O}$ アモルファス相を桩散するためと考えられる.

また， $\mathrm{Al}$ 拡散の頻度因子に関して，アモルファス相の多い
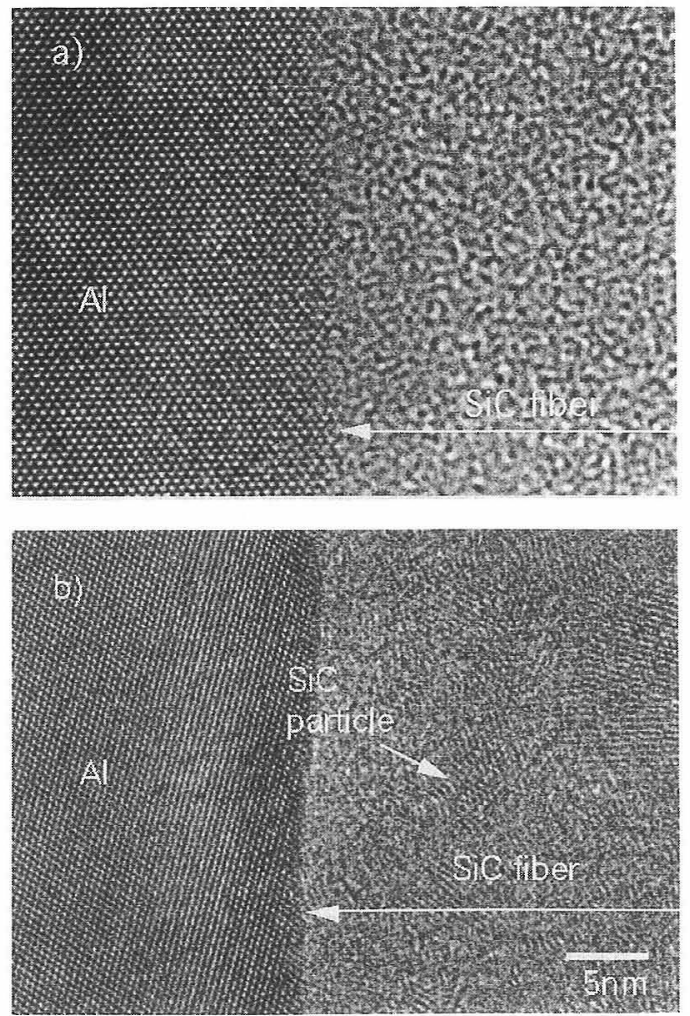

Fig. 3. TEM images shows the difference of (a) Nicalon ${ }^{\mathrm{TM}} \mathrm{SiC}$ fiber compared to (b) Hi-Nicalon ${ }^{\mathrm{TM}} \mathrm{SiC}$ fiber.
Nicalon ${ }^{\mathrm{TM}}$ 繊維の力が 2 けた大さい理由は, $\mathrm{Al}$ が $\mathrm{SiC}$ 繊維中 の $\mathrm{Si}-\mathrm{C}-\mathrm{O}$ アモルファス相を拡散し, $\mathrm{SiC}$ 紻維のナノスケール 構造が $\mathrm{Al}$ 拡散の頻度因子に大きく影響しているためと考えら れる。

なお，上記の結果に基づき, 複合電線の使用環境条件である $300^{\circ} \mathrm{C} \times 36$ 年での推定拡散距離を試算した結果, Nicalon ${ }^{\mathrm{TM}}$ 緎 維が $6.3 \times 10^{-6} \mathrm{~m}, \mathrm{Hi}-\mathrm{Nicalon}{ }^{\mathrm{TM}}$ 䋐維が4.4 $4 \times 10^{-7} \mathrm{~m}$ となる.

$15 \mu \mathrm{m}$ の $\mathrm{SiC}$ 繊維径に対して, Nicalon ${ }^{\mathrm{TM}}$ 繊維では $\mathrm{A} 1$ の拡散 距離が無視できないのに対して, Hi-Nicalon ${ }^{\mathrm{TM}}$ 繊維では $\mathrm{Al}$ の 拡散は無視できるほど小さく，長期信頼性に優れていることが 分かる. 以上の計算結果をまとめて表 1 に示す. $\mathrm{SiC}$ 繊維強化 $\mathrm{Al}$ 複合電線の使用環境下に扔いては, Hi-Nicalon ${ }^{\mathrm{TM}}$ 繊維が適 用可能であることが確認された。

今後, $\mathrm{Si}-\mathrm{C}-\mathrm{O}$ 系のナノ構造で構成された繊維の極表面にお ける $\mathrm{Al}$ 濃度の挙動などの拡散現象について, 明らかにしてい く予定である。

\section{4. 結 言}

$\mathrm{SiC}$ 繊維強化 $\mathrm{Al}$ 複合電線の使用条件下, $\mathrm{Al}$ の融点以下の温 度領域での $\mathrm{SiC}$ 䋐維/ $\mathrm{Al}$ 界面での $\mathrm{SiC}$ 繊維中への $\mathrm{Al}$ の拡散に 着目し, Nicalon ${ }^{\mathrm{TM}}$ (Si : 63.7, C : 35.8, O : 12.3 mass\%) 及び Hi-Nicalon TM (Si : 62.4, C : 37.1, O : 0.5 mass\%) 中への Al の 拡散現象を評価し, 以下の結論を得た。

(1) $\mathrm{SiC}$ 緎維中への $\mathrm{Al}$ の拡散係数は, Hi-Nicalon ${ }^{\mathrm{TM}}$ 䋐維 が Nicalon TM 繊維よりも 3 けたほど小さい.

（2） $\mathrm{SiC}$ 繊維中への $\mathrm{Al}$ の拡散の活性化エネルギーQはは ぼ等しいが, Hi-Nicalon ${ }^{\mathrm{TM}}$ 緎維の頻度因子 $D_{0}$ は Nicalon ${ }^{\mathrm{TM}}$ 繊 維に比べ 3 けたほど小さい.

（3） $\mathrm{SiC}$ 繊維中での $\mathrm{Al}$ の拡散係数は， $\mathrm{SiC}$ 緎維のナノス ケール構造と相関があると考えられる.

\section{文献}

1) K. Suzuki, Materia Japan, 36, 1075 (1997) [in Japanese].

2) A. Ozawa, T. Ishibashi, H. Kuroda and K. Nagano, 1997 National Convention Record, I. E. E. Japan (1997) No. 1352.

3) J. Sawada, T. Kikuchi, Y. Manabe, K. Nakamura, K. Nagano and $\mathrm{H}$. Kuroda, Proc, of the Eighth Annual Conference of Power \& Energy Society, I. E. E. Japan (1995) No. 574.

4) Y. Yasutomi, T. Kikuchi, J. Sawada, Y. Manabe, K. Nakamura, H. Kogure, K. Nagano, H. Kuroda, Y. Sawai and T. Kishi, Proc. of JFCC Int. Workshop on Fine Ceramics '98 (1998) pp. 257-65.

5) Y. Yasutomi, J. Sawada, T. Kikuchi, K. Nakamura, Y. Manabe, K. Nagano, H. Kuroda, T. Sumi, H. Kubokawa, M. Nagai, H. Kogure, Y. Sawai and T. Kishi, Submitted to J. Mater. Sci. (JM/70823) and (JM/70824).

6) Y. Yasutomi, J. Sawada, K. Iwai, Y. Hase, K. Nagano, H. Kuroda, T. Sumi, H. Kogure, Y. Sawai and T. Kishi, $J$. Ceram. Soc. Japan, 106, 1124-28 (1998) [in Japanese].

7) A. R. Chapman, S. M. Bleay and V. D. Scott, J. Mater. Sci., 29, 4523-34 (1994).

8) B. J. Weng, S. T. Chang and R. H. Ho, Control Interfaces Metal Ceram. Compos., 197-210 (1993).

Table 1. Diffusion of $\mathrm{Al}$ into $\mathrm{SiC}$ fibers

\begin{tabular}{cccc}
\hline SiC fiber & $\begin{array}{c}\text { Activation energy } \\
\mathrm{Q}\end{array}$ & $\begin{array}{c}\text { Frequency factor } \\
\text { Do }\end{array}$ & $\begin{array}{l}\text { Estimated depth of Al } \\
\text { diffused into SiC fiber } \\
\text { after } 300^{\circ} \mathrm{C} \times 36 \text { years }\end{array}$ \\
\hline Nicalon ${ }^{\mathrm{TM}}$ & $100 \mathrm{~kJ} / \mathrm{mol}$ & $1.2 \times 10^{-11} \mathrm{~m}^{2} / \mathrm{s}$ & $6.3 \times 10^{-6} \mathrm{~m}$ \\
Hi-Nicalon & $98 \mathrm{~kJ} / \mathrm{mol}$ & $3.8 \times 10^{-14} \mathrm{~m}^{2} / \mathrm{s}$ & $4.4 \times 10^{-7} \mathrm{~m}$ \\
\hline
\end{tabular}


9) S. L. Coleman, V. D. Scott and B. Mcenaney, J. Mater. Sci., 29, 2826-34 (1994).

10) A. H. Carim, Mater. Lett., 12, 153-57 (1991).

11) H. Liu, U. Madaleno, T. Shinoda, Y. Mishima and T. Suzuki, J. Mater. Sci., 25, 4247 (1990).

12) X.-C. Liu and K.-T. Wei, Jinshu Xuebao, 24[2], B115-20 (1988).

13) K. Matsunaga, S. Ochiai, K. Osamura, Y. Waku and T. Yamamura, J. Japan Inst. Metals, 57, 1035-40 (1993).

14) T. Shinoda, L. Hua, Y. Mishima and T. Suzuki, Bull. Japan Inst. Metals, 30, 189-98 (1991).

15) S. J. Swindlehurst and I. W. Hall, J. Mater. Sci., 29, 1075-82 (1994).
16) L. Xicong and W. Ketai, Acta Metallurgica Sinica, 24, B11520 (1988).

17) S. Towata and S. Yamada, J. Japan Inst. Metals, 47, 159-65 (1983).

18) C. Laffon, A. M. Flank, P. Lagard, M. Laridjani, P. Olry, J. Cotteret, J. Dixmier, J. L. Miquel, H. Hommel and A. P. Legrand, J. Mater. Sci., 24, 1503-12 (1989).

19) S. Yajima, K. Okamura, T. Matsuzawa, Y. Hasegawa and T. Shishido, Nature, 279, 706-07 (1979).

20) G. Chollon, M. Czerniak, R. Pailler, X. Bourrat, R. Naslain, J. P. Pillot and R. Cannet, J. Mater. Sci., 32, 893-911 (1997).

21) Y. Tajima and W. D. Kingery, J. Am. Ceram. Soc., 65, C2729 (1982). 